\title{
CONSTRUÇÃO DE SUBJETIVIDADES DE ADOLESCENTES NEGRAS: A AGÊNCIA DO RACISMO COTIDIANO
}

\author{
Rosângela Oliveira Gomes Braga iD1, Alexandre de Oliveira Fernandes (D)2
}

\section{Resumo}

Discutem-se os efeitos da colonialidade na produção de subjetividades de adolescentes do Ensino Médio do Instituto Federal de Educação da Bahia e seu desdobramento na atuação de profissionais do Serviço de Enfermagem. Demonstram-se impactos do racismo cotidiano nas subjetividades de discentes negras e a fragilidade do desempenho da enfermagem frente a essa problemática. Articulam-se obras de intelectuais negras e negros como Grada Kilomba (2019) e Frantz Fanon (2008) com nossa experiência clínica, empírica e teórica, com vistas a corroborar como as subjetividades negras podem ser acolhidas e fortalecidas em sua singularidade. Conclui-se que o cuidado e a prevenção de adoecimento mental de adolescentes negras não podem se dar sem um resgate ontológico de si, sendo o processo do fortalecimento de subjetividades tão urgente quanto o tratamento de feridas visíveis provocadas nos corpos de adolescentes negras.

Palavras-chave: Adoecimento mental; Enfermagem; Resgate ontológico.

\section{CONSTRUCTION OF SUBJECTIVITIES IN BLACK ADOLESCENTS: THE AGENCY OF EVERYDAY RACISM}

\section{Abstract}

The effects of coloniality on the production of subjectivities of high school teenagers at the Federal Institute of Education of Bahia are discussed and its effect on the performance of professionals in the Nursing Service. The impacts of everyday racism on the subjectivities of black students and the fragility of nursing performance in relation to this problem are demonstrated. Works by black and black intellectuals such as Grada Kilomba (2019) and Frantz Fanon (2008) are articulated with our clinical, empirical and theoretical experience, with a view to corroborating how black subjectivities can be welcomed and strengthened in their uniqueness. It is concluded that the care and prevention of mental illness of black adolescents cannot be done without an ontological rescue of themselves, the process of strengthening subjectivities being as urgent as the treatment of visible wounds caused on the bodies of black adolescents.

Keywords: Mental illness; Nursing; Ontological rescue.

\footnotetext{
${ }^{1}$ Mestranda em Ensino e Relações Étnico-raciais (PPGER), pela Universidade Federal do Sul da Bahia (UFSB/CSC). Técnica em Enfermagem do Instituto Federal de Educação, Ciência e Tecnologia da Bahia/Eunápolis (IFBA). E-mail: rosangela.braga@ifba.edu.br.

${ }^{2}$ Doutor em Ciência da Literatura (UFRJ). Professor no Programa de Pós-Graduação em Ensino e Relações Étnicas - PPGER, da Universidade Federal do Sul da Bahia (UFSB/CSC). E-mail: alexandre.pro@gmail.com
} 


\title{
1. Tentando me encontrar: passos iniciais para de(s)colonizar a subjetividade
}

\author{
Deixe-me ir \\ Preciso andar \\ Vou por aí a procurar \\ Rir pra não chorar. \\ Se alguém por mim perguntar \\ Diga que eu só vou voltar \\ Quando eu me encontrar [...] \\ Angenor de Oliveira ${ }^{3}$
}

Antes de iniciar estudos no mestrado profissional em Relações Étnico-Raciais, ligado ao Programa de Pós-Graduação em Ensino e Relações Étnico-Raciais da Universidade Federal do Sul da Bahia - UFSB, nosso objetivo era meramente o de contribuir para a permanência e o êxito escolar de adolescentes negras do Instituto Federal de Educação, Ciência e Tecnologia (IFBA), campus Eunápolis, tendo em vista que, em sua maioria, aquelas estudantes procuram o Serviço médico e de enfermagem (SME) da instituição com certa frequência para relatar queixas diversas.

A equipe do SME é composta por médico, enfermeira e técnica de enfermagem, e conta com o apoio de outros setores como psicologia e nutrição. Devido à complexidade dos atendimentos podem se fazer necessários encaminhamentos para outros serviços disponibilizados no campus. Dispomos da cooperação de dois profissionais do Centro de Atenção Psicossocial (CAPS), que atuam às quartas-feiras à tarde, em uma sala de acolhimento. O SME é um setor que chamamos de serviço de portas abertas, pois as(os) discentes podem comparecer ao local a qualquer momento do dia de acordo com horário de trabalho (07h - 17h), o que já não ocorre com outros setores por necessitarem de agendamento.

Já aconteceu de atendermos discentes queixando-se de mal-estar e durante a anamnese (coleta de dados através de questionários), detectarmos que não se alimentaram e estavam com fome. $E$, após a oferta de lanches apresentaram melhora do quadro clínico e retornaram para suas salas de aula. Em virtude dessas ocorrências, preparamos um pequeno espaço que funciona como copa onde deixamos alguns alimentos, café e chás para quando necessário. Percebemos que as adolescentes se sentem reconfortadas quando, durante 0 atendimento de

${ }^{3}$ Os versos da música em epígrafe foram escritos pelo poeta Candeia. A canção, na voz de Cartola (Angenor de Oliveira), também gravada pela cantora Marisa Monte e Zeca Pagodinho ganhou fama. Preciso me encontrar é uma reflexão de como os indivíduos estão à procura de um sentido, um significado na vida. Traz uma ideia de procura pelo eu, de sentimento de não saber como ser ou agir. Uma possível interpretação dessa música motiva-nos para uma reflexão quanto aos julgamentos, percepções e interesses diante de situações de confrontos diários. Em nosso caso, compreendemos que o processo de de(s)colonização, fundamental para contornar problemas da psiquê, se efetiva com as experiências de construção ou reconstrução de si e principalmente, através da supressão de atitudes racistas, preconceituosas e discriminatórias presentes no consciente e inconsciente. Logo, é importante oportunizar narrativas outras, espaços para a reflexão e a metabolização de dores causadas pela colonização, escravização e racismos cotidianos. LETRAS. Preciso me encontrar. Angenor de Oliveira, mais conhecido como Cartola. UMG, 1976. Disponível em: https://www.letras.mus.br/cartola/68347/ . Acesso em: 19 mai. 2020. 
enfermagem, oferecemos um chá como o de camomila ou passiflora. Ficam revigoradas também quando disponibilizamos alimentos sólidos, no caso de jejum prolongado.

Contudo, não estamos convencidas de que o problema seja apenas alimentar, pois, caso assim o fosse, procurariam o refeitório que distribui merenda escolar e não o serviço médico e de enfermagem. As discentes que comparecem ao serviço sentem-se acolhidas, à medida que percebem assegurada uma oportunidade de serem escutadas. Levando em conta suas principais queixas apresentadas - malestar difuso e invasor, um sentimento de vazio interior - chegamos a concluir que essas adolescentes não sofrem tanto de sintomas fixos em sua forma, mas sim, de perturbações vagas, sentimentos de vazio e uma queixa frequente que se reflete na incapacidade de sentir as coisas e as pessoas.

Em outros termos, as configurações subjetivas contemporâneas parecem favorecer o aparecimento de um sujeito que manifesta um sofrimento psíquico menos relacionado a conflitos neuróticos clássicos. Temos percebido em nossa atividade laboral, uma crescente preocupação por parte do Instituto Federal de Educação da Bahia / campus Eunápolis, acerca do perfil das(os) discentes que demandam atendimento no SME. Após reuniões dos conselhos de classe, várias são as inquietações e sugestões das/os docentes, entre as quais estão diversos encaminhamentos para o setor de saúde (médico, enfermagem, psicologia e nutrição), o que também ocorre por parte das coordenações dos cursos, setor pedagógico e serviço social. Isso nos lega um cenário de elevado quantitativo de adolescentes com sintomas de sofrimentos psíquicos, os quais têm sido identificados cada vez mais frequentemente como depressão, drogadição, bulimia, anorexia e síndromes complexas.

Esses sofrimentos psíquicos refletem uma cultura que passa por momentos de indefinições e transformações. Nessa oportunidade, pensamos que uma análise dos aspectos relacionados a essa nova demanda se faz pertinente, especialmente buscando um retorno ao processo de constituição do sujeito psíquico e dos fundamentos da colonialidade para compreender um pouco mais a respeito dos processos subjetivos contemporâneos e suas vicissitudes. A subjetividade, compreendida como processo pelo qual algo se torna constitutivo e pertencente ao indivíduo de modo singular, é um processo básico responsável pela construção do psiquismo. Seu desenvolvimento ocorre de forma contínua e entrelaçada a fatores internos e externos. De maneira que, a subjetividade contemporânea pode fomentar elevado grau de fragmentação do sujeito, sendo capaz de acarretar sofrimentos psíquicos com novos contornos.

Se acompanhamos o pensador Zigmunt Bauman (2005) temos que a modernidade liquida, enquanto civilização de acessos e superfluidade projeta corpos abjetos e sujeitos que serão tratados com refugo, tendo sua remoção social dada como certa. Logo, é imprescindível à enfermagem - circunscrita, para efeitos desse artigo, à educação, no contexto do Instituto Federal de Educação da Bahia (IFBA) estar atenta e sensível à concepção de que durante a construção do psiquismo poderão emergir sujeitos adoecidos que trazem consigo uma carga de sofrimento psíquico, muitas vezes insuportável para sujeitos vítimas de uma sociedade racista e preconceituosa, como também para aquelas(es) que de certa forma não estão preparadas(os) para uma escuta acolhedora e qualificada, pois ouvir a(o) discente 
implica em compreender as causas que a(o) adoece e buscar fortalecer sua subjetividade.

Objetivando o fortalecimento psíquico das adolescentes negras e o combate a violência decorrente do racismo e sexismo, esse estudo se faz pertinente intencionando a de(s)colonização no processo do cuidado pela enfermagem. Nesta perspectiva a enfermagem deve valorizar a escuta atenta e sensível. Escutar aqui não se limita ao ouvir no sentido de captar os sons, mas ir além, pois sugeri "ouvir de perto, ouvir o que está dentro do outro" como também "atender e recolher o que foi dito" (CAMILLO; MAIORINO, 2012, p. 550).

Estamos a questionar, por exemplo, como promover juntamente com as/os adolescentes e as/os profissionais de educação, o necessário equilíbrio emocional, se como profissionais de enfermagem também percebemos nossos inconscientes colonizados? Como colaborar para de(s)colonizar a subjetividade do outro, fonte de traumas e sofrimentos (KILOMBA, 2019) se o eu não está pronto para esse processo? Como realizar os cuidados necessários no tratamento de feridas perceptíveis nos corpos e arraigadas nas mentes de adolescentes negras?

\section{MJ nos amplia questões: não estou me sentindo bem}

Por sermos um serviço de portas abertas, há pouco tempo, enquanto estávamos preenchendo algumas fichas de atendimentos, compareceu à nossa sala uma discente, que chamaremos de MJ. Pediu para se deitar na maca. Como de praxe perguntamos se estava se sentindo mal e se queria ser consultada pelo médico. Respondeu-nos que não e que queria apenas ficar ali. Ficamos em silêncio por alguns momentos, até que a mudez foi rompida:

Tia, estou me sentido muito mal, não consigo dormir bem, meus pensamentos estão acelerados, parece que meu coração vai sair pela boca. Já tentei falar com minha mãe, mas ela acha que é frescura e que isso não é coisa de Deus. Não consigo me concentrar nas aulas, não compreendo nada. Minha mãe se recusa a comprar medicações para ansiedade e ainda fica me cobrando para estudar mais e mais. Isso está me sufocando. Como queria sumir para sempre... (MJ, Registro de Atendimento, 2019).

Houve outro silêncio, dessa vez cortante, por alguns instantes. As falas de MJ, adolescente negra, residente de bairro periférico da cidade de Eunápolis, tratavam de ansiedade, conflito familiar, um possível fundamentalismo religioso, problemas de atenção e aprendizagem. O teor do enunciado por MJ nos entristecia porque trazia uma situação dura, qual seja, a de não ter apoio familiar e ainda ser impossibilitada de utilizar a medicação prescrita para ansiedade.

Questionada se aceitaria que agendássemos um momento com a psicóloga, e se concordaria com que conversássemos com sua mãe para explicar sobre a importância de não abandonar o tratamento para ansiedade, MJ concordou, porém afirmou que sua mãe não iria nos ouvir e muito menos comprar o medicamento, pois acredita que psicólogo é coisa de louco e as medicações causam dependência.

Causa-nos estranheza que a mãe de MJ carregue consigo pensamentos retrógrados quanto ao tratamento necessário para o fortalecimento do psiquismo da filha. Pensamentos como esse incitam o movimento antimanicomial a permanecer firme em sua luta, destacando-se desde 1970 no combate a favor de direitos para as 
pessoas com sofrimento mental. Sabe-se que a luta antimanicomial busca a desconstrução da ideia de isolamento social, o internamento em hospitais psiquiátricos (SIMONETTI, 2017). Contudo, o aspecto histórico permanece influente produzindo preconceitos acerca de atendimentos relativos à psique. Embora tenha sido um tanto quanto alterada essa cultura de estereótipos, ainda está enraizada em nossa sociedade. Por esse motivo, muitas(os) pacientes preferem omitir para a família, amigas(os) e parceiras(os) a informação de que estão em tratamento psicológico, com vistas a evitar uma situação de estigmatização.

No intuito de promover condições que favoreçam a adesão ao tratamento medicamentoso quando é necessário, e também um ambiente sem estigmatização pode ser utilizada pelo profissional de enfermagem a psicoeducação ${ }^{4}$, tanto para a(o) paciente quanto para a família, propondo a promoção do conhecimento e visando favorecer uma conduta mais aderente do indivíduo à terapia. Por isso, é importante dialogar com a(o) paciente e seus familiares sobre as questões relativas à ação do medicamento no organismo, efeitos esperados, reações adversas e o tempo necessário para proporcionar uma melhora do quadro clínico.

Também é imprescindível ao profissional da enfermagem ter conhecimento mínimo sobre a classificação de pacientes psiquiátricos. Alfredo Simonetti (2017), apresenta $\mathrm{a}(\mathrm{0})$ paciente psiquiátrica(o) da antiguidade na figura da(o) louca(o) e também na figura da(o) que não é louca(o) psicótica(o), que delira, e sim a(o) depressiva(0), a(o) melancólica(0), a(o) bipolar e a(o) ansiosa(o). Já a figura do louco contemporâneo, não é aquela(e) que alucina e nem delira, não é a(o) depressiva(o) e não tem uma psicopatia grave, mas procura uma terapia, mesmo que não seja uma(um) psicopata e nem uma(um) deprimida(o). Todavia (o) paciente sofre: "E sofre de diversos tipos de sofrimentos"5". Desse modo, evidencia-se que para cada paciente existe uma conduta terapêutica diferenciada e complexa, assim como existem diferentes diagnósticos e tratamentos. Precisamos também considerar que dor e sofrimento tratam de realidades distintas. Enquanto a dor possui suporte fisiologicamente detectável, no sofrimento muitas vezes não é assim.

A falta de sensibilidade ao considerar que a dor do nível psicológico não existe, é imaginada, apenas mental, ou seja, "a mente não é de ordem fisiológica, não vive imersa num corpo" (OLIVEIRA, 2016, p. 226), ocorre, muitas vezes, pela incapacidade de identificar a causa para uma queixa de dor. Avaliamos essa percepção como irreal, nomeando-a como psicológica. Valorizar essa crença é o mesmo que tapar os ouvidos para a não escuta da(o) outra(o), correndo o risco de não atuar de forma eficaz no atendimento adequado das adolescentes.

\footnotetext{
${ }^{4}$ COFEN - Conselho Federal de Enfermagem. Anexo da resolução Cofen no 0599/2018. "Compete ao Enfermeiro cuidados de Enfermagem de maior complexidade técnica e que exijam conhecimentos científicos adequados e capacidade de tomar decisões imediatas: [...] j) Conduzir e coordenar grupos terapêuticos; k) Participar das ações de psicoeducação de usuários, familiares e comunidade; I) Promover o vínculo terapêutico, escuta atenta e compreensão empática nas ações de enfermagem aos usuários e familiares" Disponível em: http://www.cofen.gov.br/wpcontent/uploads/2018/12/Resolu\%C3\%A7\%C3\%A30-599-2018-ANEXO-APROVA-NORMA-PARAATUA\%C3\%87\%C3\%830-DA-EQUIPE-DE-ENFERMAGEM-EM-SA\%C3\%9ADE-MENTAL-EPSIQUIATRIA-ARQUIVO-EM-PDF.pdf Acesso em: 06 ago. 2020.

5 CAFÉ FILOSÓFICO CPFL. O paciente psiquiátrico na cena contemporânea. Alfredo Simonetti. YouTube. 03 de set. 2017. Disponível em: https://www.youtube.com/watch?v=L-YftfuyFxM Acesso em: 26 mar. 2020.
}

(9) (1) Perspectivas em Diálogo, Naviraí, v. 8, n. 16, p. 296-308, jan./abr. 2021. 
Não é nova a discussão acerca do sofrimento, todavia, ganha contornos diversos conforme o tempo avança. Embora a questão do sofrimento, não raras vezes, apareça envolvendo elementos de dor física, observado entre as discentes como cefaleia, epigastralgia, cansaço, insônia e artralgia, e muitas vezes medicadas conforme suas queixas, após a escuta dessas discentes, concluímos que dor e sofrimento estão interligados.

Optamos pela definição de sofrimento como sendo um estado de aflição severa, angústia, ânsia, sentimento de persistente dor física ou moral, associada a acontecimentos que ameaçam a integridade de uma pessoa. "Sofrimento exige consciência de si, envolve as emoções, tem efeitos nas relações pessoais da pessoa, e tem um impacto no corpo" (OLIVEIRA, 2016, p. 228), não à toa, MJ sentir-se mal, não conseguir dormir bem, o coração parecer que vai lhe saltar pela boca. Aflição é ainda a sensação de que algo ruim está acontecendo ou poderá acontecer, frequentemente adjunta a emoções, como ansiedade e a sentimentos, como tristeza, frustrações e impotência. Por ser de vivência interior torna possível que a enfermagem não o detecte.

O sofrimento é caracterizado pela sensação de dor, mal-estar e infelicidade. Geralmente, surge anexo a eventos externos como relacionamentos doentios com outras pessoas, outras enfermidades, desemprego, falecimento de ente querido, isto é, o sofrimento está associado a situações negativas. É importante destacar, que num estado de aflição severa pode-se lesionar algum órgão interno do corpo humano como coração e fígado. E o curioso de tudo isso, é que exames auxiliares muitas vezes podem ser ineficazes para o seu diagnóstico. Por isso, a enfermagem deve ter muito cuidado antes de concluir que nada está acontecendo de fato com a discente, pois, "ainda que a causa do sofrimento possa ser considerada exterior, não se pode confundi-la com o efeito produzido (o sofrimento), tampouco reduzi-lo àquela única causa" (OLIVEIRA, 2016, p. 228).

Sigmund Freud (2010), ao se debruçar em seus estudos sobre o sofrimento, propôs uma reflexão com seu texto: Mal-Estar na Civilização. O pai da psicanálise nos mostra situações de impasses que levam o ser humano a sofrer: o declínio natural do corpo, a imperfeição de nossas leis, as exigências internas de satisfação e uma busca constante pela felicidade. "Descobriu-se que uma pessoa se torna neurótica porque não pode tolerar a frustração que a sociedade lhe impõe, a serviço de seus ideais culturais, inferindo-se disso que a abolição ou redução dessas exigências resultaria num retorno a possibilidades de felicidade" (FREUD, 2010, p. 31). Nos dias atuais, Freud nos ajuda a compreender o mal-estar presente em nossa sociedade, provocados pelos ideais culturais e suas exigências, como depressão, ansiedade, compulsões e tantos outros sintomas individuais.

Ao longo do tempo, o sofrimento, foi reconhecido e tratado de diversas maneiras. Traçando um panorama histórico dos últimos 100 anos, o psicanalista Christian Dunker ${ }^{6}$ discorreu sobre As transformações do sofrimento psíquico, ensinando-nos que, na primeira guerra mundial, o sofrimento sobrevinha em forma de silêncio, insuficiência de palavras, entendido como subjetividade pós-traumática. Em outros termos, a subjetividade não mais se expressava através de uma queixa.

${ }^{6}$ CAFÉ FILOSÓFICO CPFL. As transformações do sofrimento psíquico. Christian Dunker. YouTube. 06 de out. 2016. Disponível em: https://www.youtube.com/watch?v=SWvjHPszmqw\&feature=youtu.be Acesso em: 29 jan. 2020. 
As palavras não seriam ditas, ocorrendo um silenciamento crasso em uma época em que relatar acontecimentos da guerra eram pertinentes, porém os soldados ficavam calados. Em 1940, a preocupação entre os clínicos era a histeria, a fobia e a neurose obsessiva. No período pós-guerra, o sofrer vem em forma de neuroses narcísicas, com as quais não se sabia como lidar, pois apresentavam um forte sentimento de inadequação. Os relatos eram de ter perdido o sentido na vida, falta de motivação, não queriam mais viver. Já em 1990, o cenário mudou, surgem os pacientes limítrofes com dificuldade de aceitar o laço com o outro. O Transtorno de Personalidade Limítrofe (TPL) afeta o modo como a(o) paciente pensa, percebe e se relaciona com os demais. Ocorre uma instabilidade prevalente do humor, dos relacionamentos interpessoais, da imagem que a pessoa tem de si mesma e do seu comportamento.

Nos anos 2000, mais uma alteração, essas formas de sofrer se catalisaram em torno das depressões, da síndrome do pânico e da anorexia. A queixa principal atualmente gira em torno da dificuldade de se relacionar com as(os) outras(os), seguida por depressão, pânico, medo e ansiedade, não muito diferente do vivido por MJ. Negligenciadas entre a família e as(os) amigas(os), devido à ignorância sobre essas formas de sofrer muitas vezes, dores psíquicas são tratadas como invenção, frescura, coisas de uma mente fraca, como falta de Deus ou possessão maligna.

\section{Faces do racismo cotidiano: dedo na ferida - de MJ a DJ}

Frantz Fanon foi um médico psiquiatra, filósofo e intelectual envolvido na luta pela independência da Argélia, sendo também um influente pensador do século XX sobre os temas de(s)colonização e psicopatologia da colonização. Através do seu livro Pele negra, máscaras brancas (FANON, 2008) impulsiona uma reflexão acerca da barbárie que é promovida pelo sistema opressor, racista e excludente, faz críticas à violência colonial, mostrando a colonização como um processo econômico, social e psíquico.

O racismo está longe de ser um problema do passado, do tempo de Fanon. Seu livro segue tão atual quanto no período em que foi publicado em 1952. E em nossa concepção, é o que mais toca o dedo na ferida daqueles (as) que se iludem com o mito da democracia racial, acreditando que vivemos em um país tropical, cordial, em que o multiculturalismo ocorre de forma harmônica e igualitária

Aprendemos com Fanon que é a partir da relação de sujeição dos colonizados aos colonos europeus que se estabelece um duplo narcisismo. Assim a representação de si dentro dessas categorias se constrói na relação de oposição ao outro. Isto é, dentro desse processo, fica apenas uma opção ao colonizado que deseja se valorizar: ocupar o lugar da(o) outra(o), acreditando que essa seja a melhor forma de sobrevivência. $A(0)$ negra(o) tenta a todo custo tornar-se branca(o) e essa negação de si coloca-a(o) como a(o) colonizada(o), numa posição neurótica.

Nas palavras de Fanon (2008, p. 95) "na medida exata em que esta sociedade Ihe causa dificuldades, ele é colocado em uma situação neurótica", num confronto psíquico contra si própria(o) e como consequência, nasce um sentimento de complexo de inferioridade. É nesse momento que o sujeito colonizador se apropria e exerce o seu poder, engendrando uma violência psíquica contra a(o) outra(o).

Porquanto o sucesso da colonização se baseia na capacidade não apenas de colonizar espaços geográficos, mas também o inconsciente, no que Fanon chamou 
de alienação colonial, reiteramos que o sucesso do racismo está em sua extensão psicológica, uma vez que seu propósito é invisibilizar, marginalizar, subalternizar e inferiorizar pessoas e grupos reprimindo-os a uma circunstância sub-humana, retirando de si qualquer possibilidade de ser. Aqui, é-lhe rebaixada a posição ontológica de ser, tornando-se um não ser, um objeto.

A alienação em questão está relacionada à vida do próprio autor e de muitas outros, negras e negros, alusivos à classe média que usufruem de certos privilégios em relação à população negra. Ao se considerarem pertencentes à civilização ocidental, negam a cor de sua pele e assim, inicia-se toda uma maratona de esforços para serem aceitas(os). Tornam-se sujeitas(os) frustradas(os) e desiludidas(os), pois ser aceita(o) é ser branca(o) e por mais que tente se aproximar disso, não se pode alterar suas origens e a cor de sua pele. Submerso pelo desejo de ser branca(o), indivíduos negros alienados pelo discurso colonial submetem-se a regras impostas por uma sociedade contaminada pelo racismo e como implicação temos o complexo de inferioridade.

Certamente, a desalienação requer uma conscientização de si e um rompimento com o mundo ocidentalizado. É necessário um movimento de encontro para com as (os) outras(os) negras(os), que possibilite a de(s)colonização da mente. Ou seja, uma desalienação psicológica. "No entanto, permanece evidente que a verdadeira desalienação da(o) negra(o) implica uma súbita tomada de consciência das realidades econômicas e sociais" (FANON, 2008, p. 28). Assim sendo, para extirpar a alienação não basta retirar as máscaras brancas, é necessário quebrar o espelho branco e todo o reflexo de imagens distorcidas produzidas ao longo da história.

Pode-se afirmar que na adolescência a construção da identidade se torna crucial. Construir uma identidade resulta em saber quem de fato é a pessoa, que valores possui, quais as direções que deseja seguir pela vida, quais os seus ideais e questionamentos (FERREIRA; FARIAS; SILVARES, 2003). A identidade é como um elemento que vai sendo adquirido aos poucos. Existe uma junção entre algo que vem de dentro (estrutura psíquica) e algo que vem de fora (fatores externos), ou seja, a identidade individual é resultado do convívio do eu com o outro, é construída em meio ao convívio com os outros, resultado da interseccionalidade entre fatores internos e externos.

A realidade externa é constituída a partir da sociedade humana representada por suas instituições e suas regras, sendo imprescindíveis as relações sociais para uma vida em sociedade. Porém, quando essa sociedade é estruturada em um contexto histórico de racismo, preconceito e discriminação acaba por promover um ambiente de relações diferenciadas e desumanas, um desequilíbrio nas relações sociais e na estruturação psíquica dos sujeitos.

Em razão da relação com a vida acontecer por meio do imaginário social, reflexo do que é continuamente reproduzido pela mídia, espaços públicos, redes socias, sistema educacional, grupo familiar e pelo sistema de justiça, ideologias podem sustentar um discurso de que tudo que é feio, selvagem, animal, inferiorizado, marginalizado, subalternizado está correlacionado ao sujeito negro, impactando fortemente em pessoas como MJ. Adolescentes negras podem acabar por internalizar registros afetivos adversos e negativos sobre si, desenvolvendo um complexo de inferioridade, uma vez que passe a acreditar em imagens distorcidas que Ihe são atribuídas pelo outro. 
Essas experiências sem um fortalecimento psíquico favorecem o surgimento de sentimentos nocivos. Além do que, a experiência histórica do processo de escravização torna-se responsável por estruturar vários aspectos da cultura e da sociedade na atualidade, cujas marcas persistem de forma profunda como a imagem de um fantasma: divisão entre "área de serviço" e "área social" relembrando a separação entre casa-grande e senzala; utilização equivocada de expressões como "denegrir", "a coisa está preta" e "passado negro", comprovam como as atitudes racistas estão incorporadas às estruturas sociais (ABUD; SIGULEM, 2017, p. 216).

É notório que abordagens policiais ocorrem de modo diferenciado entre o sujeito negro e o branco, sendo que para o primeiro ocorre em quantidade muito maior, considerados a priori suspeitos tanto pela polícia quanto pela população. As instituições de saúde também estão inclusas nessas práticas preconceituosas, uma vez que oferecem um atendimento desigual, haja vista que os profissionais da saúde tendem a não notar as desigualdades ou até mesmo a negá-las (ABUD; SIGULEM, 2017).

A diferenciação entre indivíduos negros e não negros manifestada no interior da sociedade demostra um racismo estrutural, sendo necessário entender que o racismo é real e precisa ser desconstruído, pois enquanto poder histórico, jurídico, institucional e estrutural pertence à população branca e tem a capacidade de normalizar a violência através do mito da democracia racial, o qual disfarça e mascara as barbaridades do dia a dia.

As representações negativas estão fixadas no imaginário social, e os ataques sofridos diariamente por adolescentes negras repetidamente acabam sendo naturalizados ou tidos como não existentes em consequência de um discurso coletivo que se esforça para desmentir a violência praticada. Logo, as influências que as representações negativas exercem sobre a subjetividade de uma adolescente negra são violentas e prejudiciais, pois internalizadas desencadeiam sentimentos de inferioridade e pensamentos prejudiciais sobre si mesmas.

O Brasil é o único país das américas em que se fala majoritariamente a língua portuguesa e o maior país lusófono do planeta, uma das nações mais multiculturais e etnicamente diversas em decorrência da forte imigração de outros locais do mundo. Trata-se de um país traumatizado que jamais reparou as suas dores terríveis e os sofrimentos obscenos provocados pela colonização e escravatura, um país que se coaduna com um mundo conceitual branco a produzir cotidianamente um inconsciente coletivo das pessoas negras pré-programado para a alienação, decepção e trauma psíquico, "uma vez que as imagens da negritude às quais somos confrontadas/os não são nada realistas, tampouco gratificantes" (KILOMBA, 2019, p. 40). É evidente que colonização e escravatura, que a colonialidade segue promovendo feridas profundas nos corpos negros, cicatrizes permanentes e (in)visíveis pelo pseudodiscurso democrático.

Marcas como as de outra estudante do IFBA, aqui denominada DJ, adolescente negra, a nos procurar para atendimento. Quando criança foi abandonada pelos pais biológicos, o que ainda lhe causa sofrimentos. Relatou-nos tensão muscular, sentimento de angústia, ansiedade, desânimo e tristeza profunda.

No momento de sua escuta estava com blusa de frio, mesmo estando o clima local quente. Solicitamos que retirasse uma das partes da blusa para aferição da pressão arterial e averiguamos marcas de lesão autoprovocada. Questionada durante a anamnese, informou-nos fazer uso de medicamentos ansiolíticos, no entanto, há 
alguns dias, seu medicamento acabara e seu responsável ainda não havia recebido o auxílio para comprá-los.

De início, conversamos sobre outros assuntos pretendendo alcançar a confiança da adolescente e assim colher mais informações. DJ informou-nos que há 05 anos pratica automutilação. Aproveitamos o momento e explicamos sobre automutilação, especialmente destacando que quando pessoas cortam seus corpos desejam aliviar alguma dor emocional e/ou desconforto. Perguntamos se queria conversar mais um pouco e se já havia procurado ajuda profissional.

Sinto uma tristeza muito profunda, sem vontade de comer, sem vontade de sair. Não sinto prazer em estudar. Aqui na escola não confio em ninguém. Não tenho amigas e nem amigos. Já tentei tirar a minha vida, mas não fui bemsucedida. Ninguém se importa comigo, meus pais foram embora quando eu era pequena. Minha responsável diz que meu pai era alcoólatra e espancava minha mãe até o dia que brigaram feio e ela arrumou as suas coisas e saiu sem dizer nada, nunca tive notícias. Meu pai apareceu, mas não liga para mim, tem outra mulher e outros filhos. Não tenho raiva do meu pai, mas também não tenho amor. Aqui na escola percebo que os colegas se acham superiores e mais inteligentes só porque eu vim de escola pública, sou pobre, mulher e negra. Sei que tenho muitas dificuldades em aprender, mas estou tentando, está muito difícil e complicado. Minha turma é a pior e muito desunida (DJ, Registro de Atendimento, 2019).

Percebemos em sua fala, uma conexão entre produção do racismo, tentativa de suicídio, baixa autoestima, despersonalização do sujeito negro. Levada às últimas consequências, o teor do que DJ nos propõe tem a ver com um desejo da(o) negra(o) de tornar-se branca(o), decorrência da desumanização que lhe é imposta, à forma de peles negras, máscaras brancas, induzindo no sujeito negro o desejo de abandonar o seu eu e passar a existir como outra/o.

Não desejando permanecer na invisibilidade, sem amigas e amigos na escola, o indivíduo negro procura desfazer-se do outro negativo que lhe fora incutido, dando início a uma batalha entre o eu e o outro, entre o outro e o eu.

Ocorre que o sentimento de profunda tristeza, a automutilação, o suicídio podem ser vistos como "um ato performático da própria existência imperceptível. Em outras palavras, o sujeito negro representa a perda de si mesmo, matando o lugar da Outridade", fato comprovado diante de narrativas por nós presenciadas, as quais conectam o "soma" ao impacto do racismo e do isolamento. Estamos a dizer, acompanhando Grada Kilomba que, as agressões ao corpo são resultado do emudecimento, do ficar sem palavras, uma "necessidade de transferir a experiência psicológica do racismo para o corpo - o soma - [pode ser vista como] uma forma de proteção do eu ao empurrar a dor para fora (somatização)" (KILOMBA, 2019, p. 161).

No relato de DJ fica evidente o sentimento de subjugação e os efeitos devastadores em sua subjetividade, pois, como não se sentir isolada uma vez que fora abandonada pelos pais? Como amar-se, se nem ao menos conheceu esse sentimento? Mesmo fazendo uso de medicações e terapias, é complexo desfazer-se da dor e dos traumas do racismo cotidiano.

DJ vivencia um sentimento de vazio e demonstra dificuldade em expressar sentimentos comuns, como ódio, indignação, alegria e amor. Não que esses sentimentos não ocorram, mas sente-se apática e desinteressada, tem dificuldade de chorar, sua autoestima é baixa, chegando a se definir como um lixo, sem qualquer 
importância e sem expectativa de planos futuros, daí resulta seu desejo de automutilação, algo que Ihe parece incontrolável, um vício do qual, ainda que queira, não consegue se libertar.

O conceito de trauma, originalmente derivado do grego, significa ferida ou lesão, é utilizado pela enfermagem com certa frequência para referir-se a qualquer dano em que a pele é rompida como consequência da violência externa. Trazendo esse conceito para nossa temática, o trauma é caracterizado por um evento violento na vida do sujeito em que devemos considerar sua intensidade, e principalmente, a capacidade de resposta da(0) sujeita(o) diante desse trauma, bem como seus efeitos perturbadores e o tempo de duração em que a estrutura psíquica é exposta.

A escravização, o colonialismo e o racismo cotidianos são fatores traumáticos intensos e violentos, aos quais $\mathrm{a}(\mathrm{o})$ sujeita(o) negra(o) pode ter dificuldades em responder adequadamente. Não se pode subestimar o impacto dessa violência contra as adolescentes negras. Mesmo que seus corpos apresentem feridas extensas e infectadas promovidas por uma sociedade racista e preconceituosa, necessário é limpar a ferida, realizar a remoção do tecido não viável, detritos celulares e todos os resíduos estranhos, de forma a minimizar a infecção e promover a sua cicatrização. Decerto é um procedimento doloroso, porém, imprescindível. Não há como não meter o dedo nas feridas do racismo.

\section{Considerações finais}

Em "Guerra colonial e perturbações mentais", quinto capítulo de "Os condenados da Terra", Frantz Fanon (1968) apresenta casos que podem se desdobrar em perturbações mentais, tendo como pivô uma atmosfera sanguinária, desapiedada, a generalização de práticas desumanas, a impressão tenaz de um verdadeiro apocalipse. Difícil deixarmos de trazer essas questões para nossa realidade, quando diariamente uma instituição de ensino acolhe discentes das periferias e cidades circunvizinhas, as quais remontam os mais diversos relatos, igualmente violentos, sanguinários, desapiedados e apocalípticos.

São casos de discentes violentadas fisicamente, emocionalmente e sexualmente, são estudantes que vivem em extrema miséria, muitas vezes falta-Ihes o alimento, são abandonadas e sobrevivem com qualquer outra(o) que lhe ofereça atenção, menos com os pais. São diversas histórias silenciadas e não contadas em uma sociedade opressora e estruturalmente racista.

Traçando um paralelo possível, em seus escritos, Grada Kilomba (2019) denuncia dificuldades encontradas para cursar seu doutorado na Alemanha e que por diversas vezes pensou em desistir de seus projetos diante dos obstáculos que lhe foram impostos. Uma de suas reflexões nos dá conta de como é complexo viver em uma sociedade racista, sendo ela uma das poucas intelectuais negras dentro dessa maquinaria branca, o que lhe custa muito emocionalmente.

Quantas discentes negras sentem e passam por desafios semelhantes aos de Kilomba ou vivem como condenadas da terra? Suas mentes têm turbilhões de pensamentos acerca do quanto é difícil frequentar aulas e ainda lidar com as questões da adolescência em meio à seara racista. Quando decidem procurar ajuda profissional, já apresentam sinais de desgaste emocional e cansaço físico, pois vivenciam lutas constantes até o momento em que seus corpos e mentes não 
suportam a dor e o sofrimento de estarem num ambiente que lhes nega a todo instante a existência de si.

A adolescência é constructo incorporado recentemente à história, compreendido como fase especial para autonomia psicossocial e adaptação à sociedade. É na adolescência que o cenário de extrema desigualdade, racismos cotidianos, base de nossa sociedade racista, representa um perigo em potencial para adoecimento psíquico.

A situação se torna alarmante, quando se trata de adolescentes negras que além de enfrentarem situações próprias da fase, tem que conviver com as desigualdades raciais e de gênero. É na adolescência que as experiencias negativas vão sendo internalizadas, causando impactos dolorosos, sentimentos de inferioridade, de não pertencimento, incapacidade, medo e ansiedade, por conseguinte, marcas e feridas profundas.

Não é o analgésico apenas que alivia a dor, reflexo do sofrimento psíquico, e sim o acolhimento com uma escuta atenta e antirracista, pois quando a adolescente negra externaliza as suas angústias, inquietudes, ansiedades e aflições, quando consegue romper com o silenciamento, sua mente compreende que naquele momento a escuta terapêutica lhe é importante, mesmo que o alívio seja temporário.

Assim sendo, as Instituições de Ensino - IES - devem proporcionar um ambiente acolhedor e promover aos seus servidores capacitações que incluam a temática da saúde mental para adolescentes negras. Considerando que as adolescentes negras permanecem bom tempo no ambiente escolar, fazem-se necessárias medidas com intuito de redução dos impactos causados pelo racismo cotidiano, como acesso facilitado ao setor de psicologia e, quando necessário, encaminhamento à Rede de Atenção Psicossocial disponível. É imprescindível que os profissionais da educação, juntamente com o serviço médico e de enfermagem estejam atentos aos sinais e sintomas de sofrimento psíquico, realizando cuidados e encaminhamentos, corroborando assim para um atendimento mais adequado e a solução de desigualdades e injustiças.

\section{REFERÊNCIAS}

ABUD, Cristiane Curi; SIGULEM, Luiza. A questão do racismo em um grupo de mediação com fotografias. Em: KON, Noemi Moritz; ABUD, Cristiane Curi; SILVA, Maria Lúcia da. O racismo e o negro no Brasil: questões para a psicanálise. 1 ed. - São Paulo: Perspectiva, 2017.

BAUMAN, Zygmunt. Vidas desperdiçadas. Tradução de Carlos Medeiros. Rio de Janeiro: Zahar, 2005.

CAMILLO, Simone de Oliveira; MAIORINO, Fabiana Tavolaro. A importância da escuta no cuidado de enfermagem. Cogitare Enferm. v. 17, n. 3, jul/set. 2012.

FANON, Frantz. Os condenados da Terra. Tradução de José Laurênio de Melo. Rio de Janeiro: Civilização Brasileira, 1968. 
FANON, Frantz. Pele negra, máscaras brancas. Tradução de Renato da Silveira. Salvador: EDUFBA, 2008.

FERREIRA, Teresa Helena Schoen; FARIAS, Maria Aznar; SILVARES, Edwiges Ferreira de Mattos. A construção da identidade em adolescentes: um estudo exploratório.

Estudos de Psicologia. v. 8, n. 1, 2003.

FREUD, Sigmund. O mal estar da civilização. Tradução de Paulo César de Souza. Em: FREUD, Sigmund. Obras completas. v. 18. São Paulo: Companhia das Letras, Editora Schwarcz Ltda, 2010.

KILOMBA, Grada. Memórias da Plantação: Episódios de racismo cotidiano. Tradução Jess Oliveira. Lisboa: Cobogó, 2019.

OLIVEIRA, Clara Costa. Para compreender o sofrimento humano. Rev. Bioét., Brasília, v. 24, n. 2, ago. 2016.

\section{Referência Videográfica}

As transformações do sofrimento psíquico. Christian Dunker. Café Filosófico CPFL. YouTube Vídeo Editor (1:45:04). 06 de out. 2016. Disponível em: https://www.youtube.com/watch?v=SWvjHPszmqw\&feature=youtu.be Acesso em: 29 jan. 2020.

O paciente psiquiátrico na cena contemporânea. Alfredo Simonetti. Café Filosófico CPFL. YouTube Vídeo Editor (48:27). 03 de set. 2017. Disponível em: https://www.youtube.com/watch?v=L-YftfuyFXM Acesso em: 26 mar. 2020.

Recebido em: 08 de agosto de 2020. Aceito em: 13 de novembro de 2020. Publicado em: 05 de janeiro de 2021. 